\title{
Brain 'imaging' in the Renaissance
}

\author{
Alessandro Paluzzi ${ }^{1} \quad$ Antonio Belli ${ }^{2}$ Peter Bain ${ }^{3} \quad$ Laura Viva ${ }^{4}$
}

J R Soc Med 2007; 100:540-543

\section{SUMMARY}

During the Renaissance, a period of 'rebirth' for humanities and science, new knowledge and speculation began to emerge about the function of the human body, replacing ancient religious and philosophical dogma. The brain must have been a fascinating mystery to a Renaissance artist, but some speculation existed at that time on the function of its parts. Here we show how revived interest in anatomy and life sciences may have influenced the figurative work of Italian and Flemish masters, such as Rafael, Michelangelo and David. We present a historical perspective on the artists and the period in which they lived, their fascination for human anatomy and its symbolic use in their art.

Prior to the 16th century, knowledge of the brain was limited and influenced in a dogmatic way by the teachings of Galen ${ }^{1}$ who, as we now know, conducted his anatomical studies not on humans but on animals. ${ }^{2}$ Nemesus, Bishop of Emesa, in around the year 400 was one of the first to attribute mental faculties to the brain, specifically to the ventricles. He identified two anterior (lateral) ventricles, to which he assigned perception, a middle ventricle responsible for cognition and a posterior ventricle for memory. ${ }^{2,3}$ After a long period of stasis in the Middle Ages, Renaissance scholars realized the importance of making direct observations on dissected cadavers. Between 1504 and 1507, Leonardo da Vinci conducted experiments to reveal the anatomy of the ventricular system in the brain. He injected hot wax through a tube thrust into the ventricular cavities of an ox and then scraped the overlying brain off, thus obtaining, in a simple but ingenious way, an accurate cast of the ventricles. ${ }^{2,4}$ Leonardo shared the belief promoted by scholarly Christians that the ventricles were the abode of rational soul.

We have several examples of hidden symbolism in Renaissance paintings, but the influence of phrenology and this rudimentary knowledge of neuroanatomy on artists of

${ }^{1}$ Department of Neurosurgery, James Cook University Hospital, Middlesbrough, UK

${ }^{2}$ Division of Clinical Neurosciences, University of Southampton, Southampton, UK

${ }^{3}$ West London Neurosciences Centre, Charing Cross Hospital, London, UK ${ }^{4}$ Department of Radiology, James Cook University Hospital, Middlesbrough, UK Correspondence to: Mr Alessandro Paluzzi, 18 Collingham Drive, Nunthorpe, Middlesbrough TS7 0GB, UK that period is under-recognized. In the absence of documentary or scientific evidence as to the real intentions of these painters, the notion of such commixture of sacred and profane remains speculative and probably controversial, but at the same time fascinating and provocative. Here we present three examples of Renaissance masterpieces where such symbolism may have been used, although probably many more exist. Conducting an artistic, philosophical and anatomical analysis of the paintings can be an intriguing exercise, but the interpretation will inevitably be conjectural.

\section{RAFAEL'S TRANSFIGURATION OF JESUS}

'Clothed in snow-white garments, Christ seems, as he opens his arms and raises his head, to display the essence and godly nature of all three Persons of the Trinity, closely united in the perfection of Raphael's art.' 5

This painting combines two separate, though consecutive, episodes of the Gospels in the same picture: the 'Transfiguration of Christ on Mount Tabor' and the 'Healing of the Boy with an Evil Spirit'. Before Raphael these episodes had been represented in some cyclical illustrations, but never together in the same painting. Jesus appears to be surrounded by a circular or spherical cloud, into which the main figures are almost perfectly inserted. Everything in the painting seems to follow a geometrical order. The circle, however, is not symmetrical, being notched on the right hand side (Figure 1). This notch is the first feature that suggests that the cloud might have been modelled to a specific design. As we follow the contour of the cloud where the lines assume more definition, what seems to be just a cloud takes on a very peculiar shape.

It may not be immediately obvious at first sight (and perhaps it was not meant to be) but, as Figure 2 illustrates, the picture has a striking resemblance to a human brain.

The right panel of Figure 2 shows the medial aspect of the right hemisphere in a brain halved along its sagittal plane. The above-mentioned notch in the cloud on the right side of Jesus represents the Sylvian fissure that divides the temporal from the frontal lobe. The inner part of the temporal lobe 'hooks in' between the figures of Jesus and Elijah, representing the uncus of the temporal lobe.

Elijah's silhouette has an astonishing similarity to the brain stem: the floating part of his garments on the right side neatly portrays the pons Varolii, whilst around and 


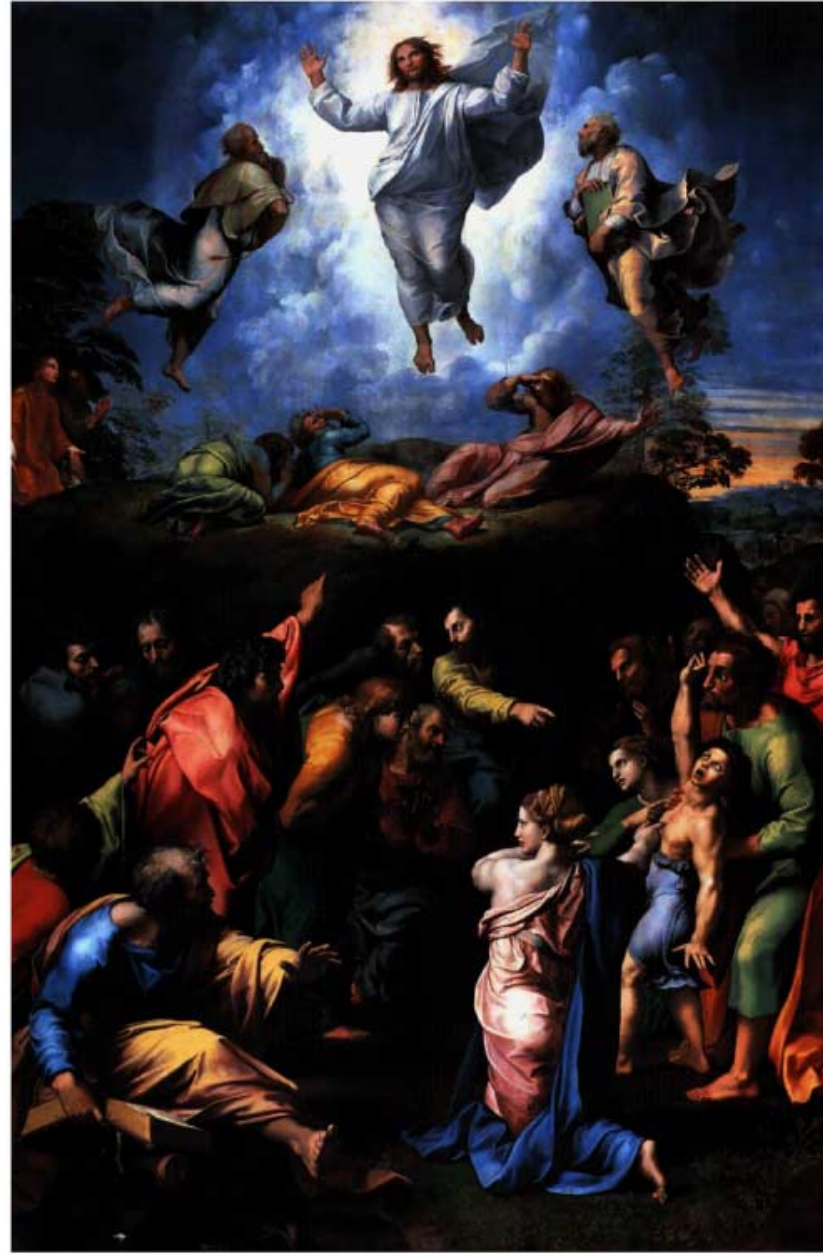

Figure 1 The Transfiguration of Christ (1517-1520). Rafael Sanzio. Vatican Museum, Rome. [In colour online.] below his left arm the robe forms two folds that describe the superior and inferior colliculi of the quadrigeminal plate. The left side of his mantle continues down to a pointed edge that outlines the shape of the cerebral aqueduct and the fourth ventricle (coincidentally, the anatomical names for the posterior wall of these two structures are the superior and inferior medullary 'vela'). Elijah's left leg continues as the bulb and the spinal cord. Jesus's contour follows the outer border of the lateral ventricles along the corpus callosum, while his robe spreads to the right, taking the shape of the third ventricle. Through the Holy Spirit, depicted as the brain, Jesus heals the lunatic boy. He gives back to the possessed boy his soul and, with it, his Reason.

\section{GERARD DAVID'S TRANSFIGURATION OF CHRIST}

Figure 3 shows how Gerard David's painting of the 'Transfiguration of Christ' resembles a coronal section of the brain.

In David's Transfiguration we find again the concept of the ventricles as the abode of the soul. God is represented in the third ventricle, with Elijah and Moses in the temporal horns of the lateral ventricles. Jesus, conduit between the Word of God and the human race, resembles the brain stem/spinal cord, conveying the message from the brain to limbs and organs.

Although little is known about this Flemish painter's life, some scholars assert that he visited Italy in 1511, where he came across the work of Leonardo, Michelangelo and Rafael. Increasingly, from the 16th century onwards,
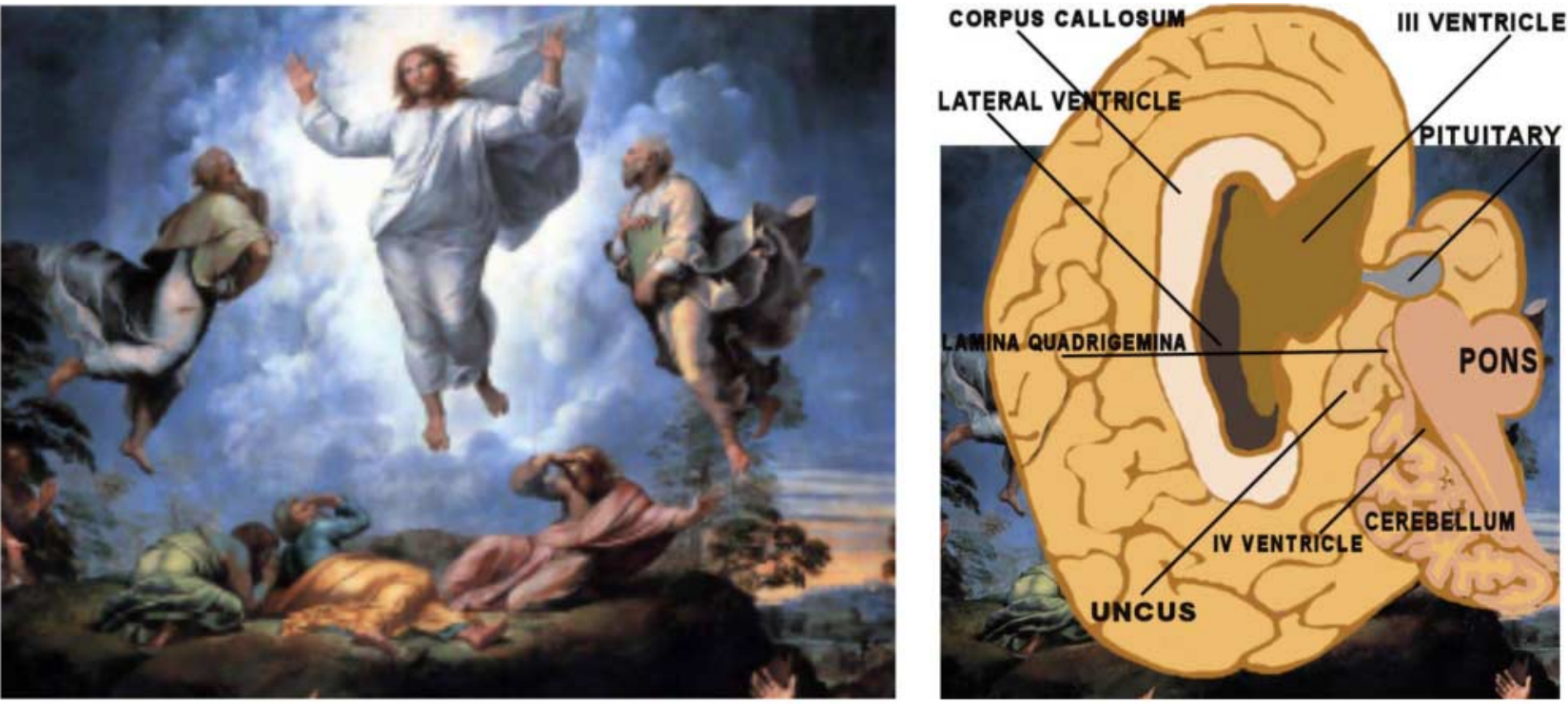

Figure 2 Left panel: blow up of the upper half of the painting. Right panel: Drawing of midline sagittal section of the human brain. [In colour online.] 


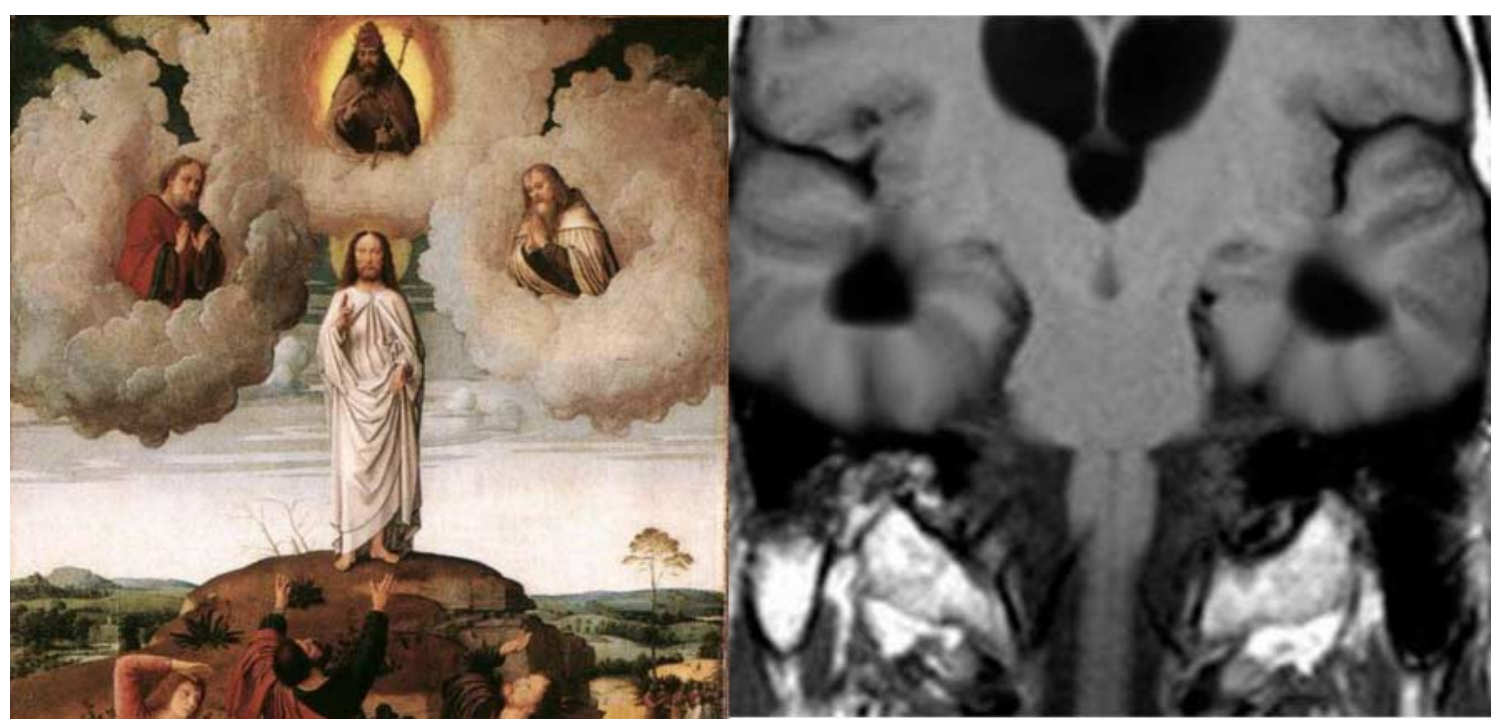

Figure 3 Left panel: blow up of the upper half of the painting. Right panel: Drawing of midline sagittal section of the human brain. [In colour online.]

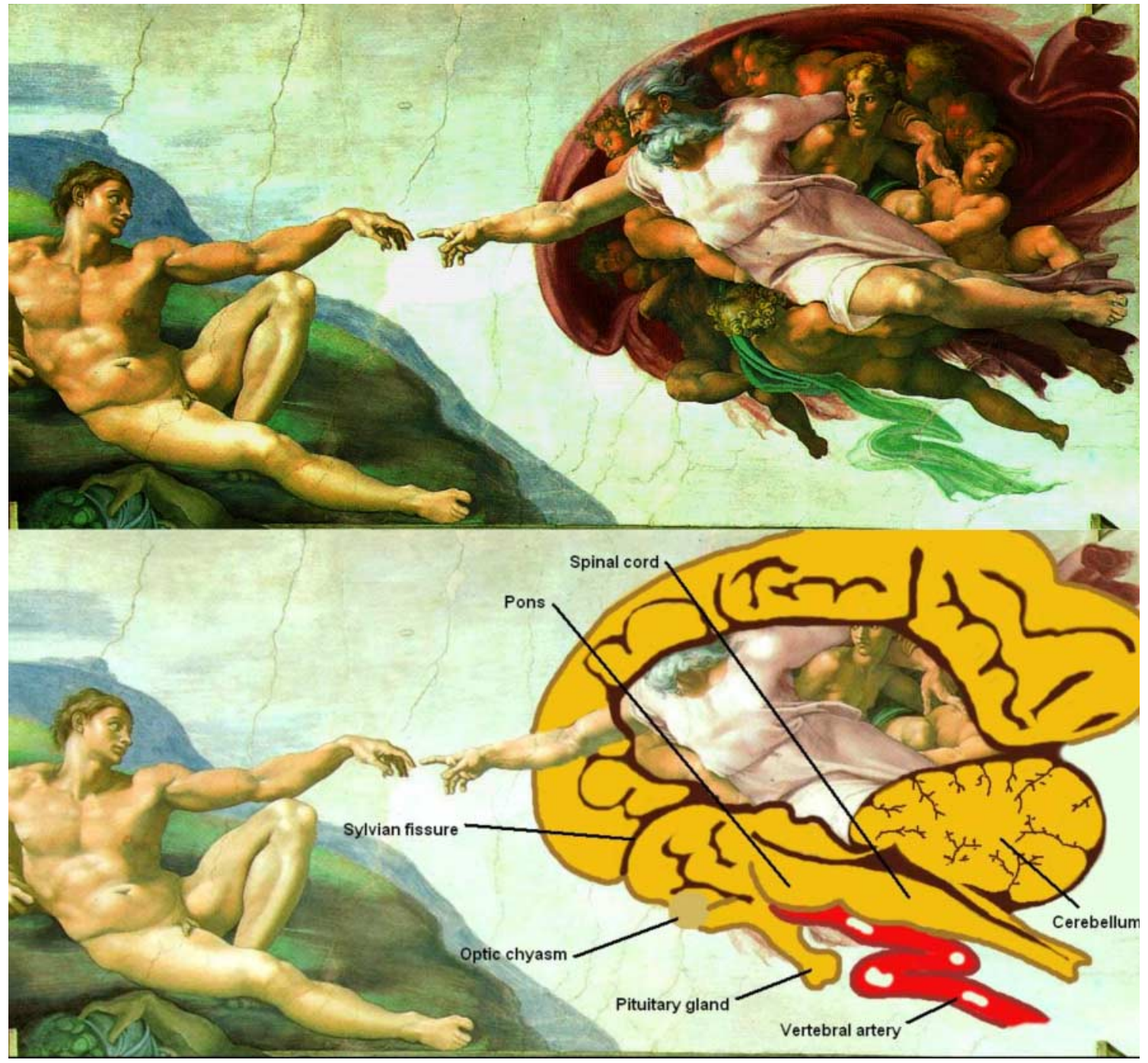


northern artists would finish their artistic education by visiting Italy.

\section{MICHELANGELO'S CREATION OF ADAM}

Raphael and Michelangelo, like Leonardo, performed numerous cadaver dissections to expand their perspective in sculpture and painting. ${ }^{5}$ More than fifteen years ago, Meshberger' 6 noted how the 'Creation of Adam' represented in the Sistine chapel (Figure 4), shows God surrounded by a drape that has the shape of what he believed to be the sagittal section of a human brain.

Starting from God's hand and proceeding anticlockwise, it is possible to recognize a fold in the cape that would correspond to the Sylvian fissure; then the cherub's right thigh represents the optic nerve, the right knee the transacted optic chiasm and the right leg the optic tract. The same cherub's left bifid foot and leg take the shape of the pituitary gland with its stalk. The flowing green robe at the base corresponds to the vertebral artery as it describes a genu before entering the foramen magnum. The back of the angel below God represents the pons, while the angel's hip and leg continue as the spinal cord. The interpretation of this scene given by Meshberger is that God, in the process of creating Adam, gives him the gift of 'intellect', symbolized by the brain. ${ }^{6}$

\section{CONCLUSION}

We are not able to explain every feature of these masterpieces: we do not know how accurately the three artists sketched the brain in their studies on cadavers, if these ever took place, and how meticulous they intended to be with their anatomical detail. To some extent this is irrelevant: the Transfiguration of Christ and the Creation of Adam are not tables of an atlas of anatomy but works of art, and they need to obey aesthetic and geometrical rules first.
Nor can we explain why the artists might have been drawn to the use of such hidden symbolism in their work: perhaps this was a tongue-in-cheek send-up of religious themes, unbeknownst to the commissioners of the paintings, or maybe just the product of a new philosophical climate where a revitalized passion for life sciences was permeating all aspects of society, including art.

Opinions amongst readers of this article will certainly vary, but we hope that this review will at least stimulate further scientific or scholarly contributions to this fascinating topic.

Competing interests None declared.

Funding None.

Ethical approval Not required.

Guarantor AP.

Contributorship $\mathrm{AP}, \mathrm{AB}$ and $\mathrm{PB}$ made the initial observations on the paintings. $\mathrm{AP}$ and $\mathrm{AB}$ wrote most of the article. LV did the drawings and literature search.

\section{REFERENCES}

1 Schiller F. The cerebral ventricles. From soul to sink. Arch Neurol 1997; 54:1158-62

2 Finger S. Minds Behind the Brain: A History of the Pioneers and their Discoveries. New York: Oxford University Press, 2000

3 Manzoni T. The cerebral ventricles, the animal spirits and the dawn of brain localization of function. Arch ItalBiol 1998;136:103-52

4 Del Maestro RF. Leonardo da Vinci: the search for the soul. J Neurosurg 1998;89:874-87

5 Vasari G, Bondanella JC, Bondanella PE. The Lives of the Artists. New York: Oxford University Press, 1991

6 Meshberger FL. An interpretation of Michelangelo's Creation of Adam based on neuroanatomy. JAMA 1990;264:1837-41 